\title{
CURRÍCULOS NOS COTIDIANOS: VIVÊNCIAS CORPORAIS NA PERSPECTIVA DOS JOGOS COOPERATIVOS PARA ALUNOS DO PROEJA
}

\section{DANUSA SIMON ROBERS}

Instituto Federal do Espírito Santo

E-mail: danusa@ifes.edu.br

\section{RITA VILANOVA PRATA}

Universidade Federal do Rio de Janeiro

E-mail: vilanova.rita@gmail.com

\section{RESUMO}

Este artigo é parte de uma pesquisa de doutorado, em andamento, e dialoga com as inventividades e agenciamentos dos sujeitos praticantes que protagonizam e realizam os currículos nas redes de saberesfazeres. Nosso caminho metodológico é permeado pelo método cartográfico e pela pesquisa com os cotidianos. Problematizamos um percurso em torno da produção de subjetividades no processo educativo durante o curso da disciplina de Educação Física no Proeja/Ifes a partir da emergência de se criar outras ordens educacionais, mais potentes, que incentivem a constituição e cuidado de si, reconhecendo o outro como legítimo outro na convivência. Através das vivências corporais na perspectiva dos jogos cooperativos, nosso objetivo foi desmitificar a necessidade do incentivo a competição - tão caro ao modelo tradicional de Educação Física - e propor a cooperação como alternativa para a ética e estética da existência - produção de uma vida bonita, e, consequentemente, de uma sociedade mais competente e menos competitiva.

\section{PalaVRas-ChaVE:}

Proeja; Ifes; Cotidiano; Educação Física; Jogos Cooperativos.

\section{CURRICULUM IN THE QUOTIDIAN: BODILY EXPERIENCES FROM THE PERSPECTIVE OF COOPERATIVE GAMES FOR PROEJA STUDENTS}

\begin{abstract}
This paper is part of our doctoral research, which is in progress, and it dialogues with the inventiveness and agency of the subject practitioners who lead and develop the curriculum on knowledge-doings networks. Our methodological path was built from the cartographic method and by research on quotidian. We have problematized the production of subjectivities in educational processes in Physical Education classes for Young and Adult Education (Proeja/Ifes) motivated by the urgent need of creating more powerful educational orders, which encourage formation and self care, recognizing the other as a legitimate other in interaction. From the perspective of cooperative games, through bodily experiences, we aimed at demystifying the need of encouraging competition - which is so valued on the traditional model of Physical Education - and at proposing cooperation as an alternative way to ethics and aesthetics of existence - production of a pretty life and, thus, of a more competent and less competitive society.
\end{abstract}


KEYWORDS:

Proeja; Ifes; Quotidian; Physical Education; Cooperative Games.

\section{INTRODUÇÃO}

Tecemos a escrita desse artigo, parte de nossa pesquisa de doutorado em andamento, compondo com o conceito foucaultiano do "cuidado de si" (1985), reconhecimento do "outro como legítimo outro na convivência" de Humberto Maturana (2009), o lema de Fábio Brotto "se o importante é competir, o fundamental é cooperar" (2003), as artes de ser/fazer e reinventar-se dos "sujeitos ordinários do cotidiano" de Certeau (1994), a "filosofia da diferença" de Deleuze (2013) e as maneiras de sentir e inventar o "currículo vivido nos cotidianos" de Alves (2008) e Ferraço (2008).

Apresentamos algumas vivências corporais (slackline, parkour, futsal de mãos dadas, brincadeiras aquáticas, dança, luta, entre outros) experienciadas pelos alunos do Proeja Cad e Proeja Guia de Turismo do Ifes campus Vitória, durante as aulas de Educação Física destacamos as formas de reinvenção das práticas através dos Jogos Cooperativos (BROTTO, 2003).

Mergulhados nos cotidianos do Proeja ${ }^{1}$ nos lançamos a observar o modo como nossos alunos pensam, vivem, sentem e produzem o mundo. Em relação de afeto e afecção (DELEUZE, 2013) não nos interessa tratar especificamente a partir das orientações acadêmicas ou políticas, mas tecer, com eles, redes de sentidos que tragam à tona outros modos de pensar sua educação.

Problematizamos, assim, um percurso em torno da produção de subjetividades no processo educativo durante o curso da disciplina de Educação Física no Proeja/Ifes

\footnotetext{
${ }^{1}$ Alunos das turmas de Educação de Jovens e Adultos do turno noturno e trabalhadores e pais e mães e filhos e filhas, e homens e mulheres, e estudantes impregnados de suas histórias de vida, das marcas que trazem da escolarização tardia, das experiências e recordações dos tempos anteriores na escola. Sujeitos ordinários do cotidiano que protagonizam nossos movimentos de pesquisa nos espaços-tempos da escola.
} 
a partir da emergência de se criar em outras ordens educacionais, mais potentes, que incentivem a constituição de si na convivência ética com o outro (FOUCAULT, 1985).

Por meio das vivências corporais na perspectiva dos jogos cooperativos, nosso objetivo foi desmitificar a competição - tão cara ao modelo tradicional de ensino da Educação Física - como a única possibilidade de experienciar as modalidades esportivas. Antes, buscamos a cooperação como alternativa para a produção de uma vida com sentido.

Segundo Orlik (1989), citado por Brotto (2003) os jogos tornaram-se um espaço de tensão e ilusão, dentro de uma sociedade competitiva. Então, resgatar, recriar e difundir os jogos cooperativos é um exercício de potencialização de valores e atitudes, capaz de favorecer o desenvolvimento de uma sociedade humana, transformando-a numa sociedade altamente competente - que é diferente de competitiva.

Os jogos cooperativos consistem em práticas de atividades da Educação Física que promovem um ambiente de coletividade e auxílio mútuo entre os participantes. O foco de seus objetivos está na resolução de tarefas e desafios que permitam participação e integração de todos. Num clima descontraído, promovido pela interação das vivências corporais, busca-se estabelecer relações de confiança, empatia, ajuda, respeito à diferença e, principalmente, repensar-se a convivência não apenas em situação de jogo, mas como metáfora de vida. A ideia é que as pessoas se percebam como parceiros e não como adversários. Prima-se pela cooperação em detrimento da competição. Por meio dessa ferramenta didática, os alunos são desafiados a pensar e a agir coletivamente, cuidando de si enquanto cuidam do outro.

A ideia não é utilizar os jogos cooperativos como uma tábua de salvação, mas como uma possibilidade, alternativa e nova perspectiva de ensino e estímulo a relações éticas de convivência que respeitem o outro como legítimo outro, auxiliando a refletir sobre ações mais solidárias e com pensamento de grupo-equipe. 
"O Jogo e o Esporte na perspectiva dos Jogos Cooperativos, são contextos extraordinariamente ricos para o desenvolvimento pessoal e a convivência social". Quando jogamos cooperativamente podemos nos expressar autêntica e espontaneamente, como alguém que é importante e tem valor, essencialmente, por ser quem é, e não pelos pontos que marca ou resultados que alcança. Dessa forma, podemos aprender que o verdadeiro valor do Jogo e do Esporte, não está em somente vencer ou perder, nem em ocupar os primeiros lugares no pódium, mas está, também e fundamentalmente, na oportunidade de jogar juntos para transcender a ilusão de sermos separados uns dos outros, e para aperfeiçoar nossa vida em comum-unidade" (BROTTO, 1999, p. 5).

Quando Foucault (1985) vai estudar os gregos e debruça-se sobre as relações de amizade e cuidado, ele cunha o termo e demonstra que o cuidado de si está necessariamente associado ao agir eticamente. Não é um cuidado individual e narcisista, mas vinculado ao cuidado com o outro. A ideia é de um sujeito livre, que se autodomina e, a partir de um agir eticamente, se relaciona com os outros.

A obra de Maturana (2009) se concentra principalmente em um termo que ele criou unindo duas palavras gregas: "auto" (para si mesmo) e poiesis (criação). A teoria da autopoiese também conhecida como "biologia do conhecer" nos aponta a capacidade dos seres vivos de produzirem a si próprios.

Maturana e Varela (1995) nos fazem perceber que os processos vitais e os processos de conhecimento são no fundo a mesma coisa. Dessa forma, a proposta de produção de uma vida bonita implica potencializar um "conhecimento bonito", isto é, um conhecimento que possa se traduzir no cuidado de si, numa relação ética e estética que respeite e reconheça o outro como legítimo outro na convivência, onde não há investimento na vida, não há possibilidade de criação de conhecimento e vice versa...

Assim sendo, buscamos romper com alguns padrões hegemônicos de influência da Educação Física (militarismo, medicina e esportivização) e permitir-nos lançar a um novo modelo de aula-vivência e de conhecimento rizomático com foco na corporeidade e cultura corporal de movimentos, potencializando outras relações e oportunizando experiências e discussões diversas através dos jogos cooperativos. 
2. Metodologia: Caminhos Possíveis...

Nosso caminho metodológico entrelaçou os estudos com os cotidianos (ALVES, 2008; FERRAÇO, 2008) e a cartografia (DELEUZE; GUATTARI, 1995; KASTRUP, 2007), tendo os alunos do Ifes Campus Vitória dos cursos do Proeja Guia de Turismo e CAD como protagonistas. Essa opção se deu considerando a complementaridade dessas propostas e os modos como relacionam a postura do pesquisador em campo e as inventividades cotidianas (CERTEAU, 1994), fluxos, agenciamentos e relações de afeto e afecto (DELEUZE, 2002).

O método cartográfico se constitui em um acompanhamento de processos através das pistas percorridas pelo pesquisador que pode se deslocar por inúmeros caminhos/territórios que se apresentam/formam ao caminhar. Aproxima-se da ideia de um rizoma². Enquanto processo metodológico é aberto para outras entradas, combinações, rupturas, conexões, desdobramentos, intensidades...

"A cartografia é um método formulado por G. Deleuze e F. Guattari (1995) que visa acompanhar um processo, e não representar um objeto. Em linhas gerais, trata-se sempre de investigar um processo de produção. De saída, a ideia de desenvolver o método cartográfico para utilização em pesquisas de campo no estudo da subjetividade se afasta do objetivo de definir um conjunto de regras abstratas para serem aplicadas. Não se busca estabelecer um caminho linear para atingir um fim. A cartografia é sempre um método ad hoc. Todavia, sua construção caso a caso não impede que se procure estabelecer algumas pistas que têm em vista descrever, discutir e, sobretudo, coletivizar a experiência do cartógrafo". (KASTRUP, 2007, p.15)

Os estudos com os cotidianos em suas redes permanentemente modificadas pelas relações, interações, saberes, fazeres, poderes, busca agenciamentos e possibilidades em detrimento do determinismo das explicações. Seus movimentos

\footnotetext{
2 O rizoma se contrapõe à metáfora arbórea do conhecimento hierarquizado. Num rizoma não se obedece a uma organização sequencial, mas utiliza-se das conexões trazendo outras possibilidades e interações, reunindo diferenças e multiplicidades. "Um rizoma não começa nem conclui, ele se encontra sempre no meio, entre as coisas, inter-ser, intermezzo. A árvore é filiação, mas o rizoma é aliança, unicamente aliança. A árvore impõe o verbo sser', mas o rizoma tem como tecido a conjunção =e... e... e...'. Há nesta conjunção força suficiente para sacudir e desenraizar o verbo ser [...]. Entre as coisas não designa uma correlação localizável que vai de uma para outra e reciprocamente, mas uma direção perpendicular, um movimento transversal que as carrega uma e outra, riacho sem início nem fim, que rói suas duas margens e adquire velocidade no meio" (DELEUZE; GUATTARI, 1995, p. 36).
} 
teórico-metodológicos vão para além das relações de causa e efeito ou de categorias e estruturas de análise.

\begin{abstract}
"Assim, nossa metodologia de estudo da escola é fortemente centrada na vida cotidiana e na valorização das ações de resistência e sobrevivência das professoras e seus alunos(as). Uma metodologia de pesquisa das práticas concretas e das artimanhas produzidas e compartilhadas. Uma metodologia do que é feito e como é feito. Neste enfoque metodológico, assumimos que não existe um único, mas diferentes caminhos. Caminhos percorridos por cada sujeito na diversidade de ações, representações e interações realizadas/vividas. Caminhos complexos, acidentais, plurais, multidimensionais, heterárquicos, fluidos, imprevisíveis, que se abrem e se deixam contaminar, permanentemente, pelas ações, pensamentos e imagens do mundo contemporâneo, enredando representações, significados e pessoas. Uma complexidade que não se esgota nunca e que, apesar de estar em todo lugar, não se deixa capturar. No máximo, ser vivida e, com alguma dose de sorte, ser sentida" (FERRAÇO, 2008, p. 112).
\end{abstract}

Por meio de rodas de conversas ao término da aula, registros no diário de campo, fotografias e portfólio dos alunos, bem como de conversas despretensiosas nos corredores, nossos movimentos de pesquisa foram tecidos. Experiências - no sentido Larrosiano ${ }^{3}$, tensionamentos e registros (nossos) e dos alunos, a partir de suas vivências nas aulas sob a perspectiva da cooperação e do cuidado mútuo consigo e com os outros, ampliaram os fios das redes de sentidos.

Kastrup, 2007 nos apresenta a atenção do pesquisador cartógrafo em campo e aponta suas quatro vertentes: rastreio - seguir os fluxos sem foco definido; toque - ser afetado pelos acontecimentos e suas imprevisibilidades; pouso - perceber com todos os sentidos as intensidades vividas; e reconhecimento atento - analisar os contornos da pesquisa e incorporar outros possíveis às suas compreensões produzindo conhecimento.

Seguimos tateando labirinticamente: ora pousando, ora nos afastando um pouco para ajustar o foco e dar novo zoom... agenciamentos que nos tomam e

\footnotetext{
3 Para Larrosa (2004, p. 163), a experiência é "aquilo que nos passa, ou nos toca, ou nos acontece, e, ao nos passar, nos forma e nos transforma". 
escapam em linhas de fuga, reterritorializando a todo tempo. E assim a pesquisa com os cotidianos e a cartografia foram rizomatizando, ganhando novas formas e a todo o tempo buscávamos perceber/sentir a escola como aquilo que entendemos que ela é: espaçotempo de produção de conhecimento e de vida. As práticas dos sujeitos foram sendo problematizadas num movimento de reinvenção das teoriaspráticas que tencionam nossa maneira de ensinaraprender em meio às redes de conhecimento que são tecidas com outros tantos cotidianos. Temos assim que a Cartografia não se ocupa da linearidade de fatos e representações, mas de acontecimentos e suas intensidades.

A composição de territórios se dá por meio de agenciamentos, inter-relações, linguagens, expressões, sensações, afetos... não se fixam. Estão sempre em constante deslizamento e formando novos territórios. Alguns comportamentos e habilidades são requeridos e esperados do aluno na EJA nas aulas de Educação Física, formando um território específico. Ocorre que os tensionamentos e tencionamentos, nessa rede pelas relações que ocorrem nos cotidianos, estão em deslizamento permanente e em constantes linhas de fuga, compondo, assim, novos territórios. As territorialidades são, pois, atravessadas, de um lado a outro, por linhas de fuga que dão prova da presença, nelas, de movimentos de desterritorialização e reterritorialização (DELEUZE; GUATTARI, 1995, p. 69).

Durante as aulas, em muitos momentos, saímos de um território que advoga o aluno trabalhador como alguém que não precisa ter acesso às práticas corporais para um território onde os alunos participam das vivências, e têm a oportunidade de se expressar e modificam todo o contexto inicialmente apresentado. Subvertem o previsto para a aula e trazem novos contornos e possibilidades a partir dos desafios apresentados. Questionam. Repensam suas atitudes e têm a oportunidade de experienciar novas formas de praticar o cuidado de si e de respeitar o outro como legítimo outro na convivência. Fazem dos jogos cooperativos uma metáfora de vida. 


\title{
3. RESULTADOS E DISCUSSÃO: DIÁlOgOS POSSÍVEIS...
}

$\mathrm{Na}$ intensidade do vivido, ao estar nas aulas com os alunos percebemos nos cotidianos as artes de ser e as possibilidades de reinvenções (CERTEAU, 1994) dos currículos da Educação Física a partir das discussões sobre corporeidade e utilizandose dos jogos cooperativos como alternativa que venha compor um currículo que potencialize a vida, que convide cada um a fazer de sua vida uma obra de arte a partir do cuidado de si e do outro possibilitando, nessa interação, a ética e a estética da existência (FOUCAULT, 1984).

\begin{abstract}
"De que valeria a obstinação do saber se ele assegurasse apenas a aquisição dos conhecimentos e não, de certa maneira, e tanto quanto possível o descaminho daquele que conhece? Existem momentos na vida onde a questão de saber se se pode pensar diferente do que se pensa, e perceber diferentemente do que se vê, é indispensável para continuar a olhar ou a refletir" (FOUCAULT, 1985, p. 13).
\end{abstract}

Impactados pela pergunta de Deleuze, a partir de sua leitura de Espinoza: O que pode o corpo? Mobilizamos nosso pensamento a esse entrelugar Educação FísicaProeja, buscando propor outros sentidos-experimentações para a prática da Educação Física subvertendo a forma hegemônica dessa disciplina nos currículos prescritivos. Dessa forma, a pergunta "O que pode o corpo?" pressupõe outra: "De que afetos um corpo é capaz?".

A partir de Espinosa, Deleuze (2002) defende que não definimos um homem por sua forma, por seus órgãos e suas funções e, muito menos, como um sujeito, mas pelos afetos (ou afectos) de que ele é capaz. Assim sendo, mobilizou-nos a seguinte questão:

Que afectos somos capazes de produzir no encontro com os estudantes do Proeja, por ocasião de práticas diferenciadas de Educação Física? O que interessa aqui está no que se passa "entre" esses corpos, os afectos de que eles são capazes e não as individualidades ou os sujeitos em si. 
Dessa forma, apresentamos um recorte das propostas de atividades desenvolvidas, conforme passamos a explicitar:

a) Dinâmica com balões: (cada aluno recebe 1 balão e 1 palito e a seguinte regra: ao final de 5 minutos, quem estiver com o balão cheio ganhará um prêmio. Normalmente começa a correria para um estourar o balão do outro. Todos os balões acabam estourados e aí refletimos: a regra não disse para estourar o balão do outro. Todos poderiam ter ganhado se ninguém estourasse o balão de ninguém. Estamos tão condicionados a competir, que nem pensamos direito e já vamos buscando ganhar, mesmo que, para isso, necessariamente, alguém tenha que perder!) introdução ao conceito de jogos cooperativos, oportunidade de conversar sobre valores, escuta sensível, empatia, competição - na vida, no mercado de trabalho, pelo assento no ônibus - solidariedade e cooperação.

b) Futsal em dupla (jogado de mãos dadas, apenas a mulher faz gol, se soltar as mãos é falta): estabelecimento de ritmo/combinação de passada, conhecer o limite do outro, coordenar a corrida, a direção, estabelecer confiança e sentir segurança que você não será puxado ou irá cair.

c) Vôlei adaptado (jogado utilizando uma canga segurada por todos da equipe): coordenar movimentos, direção, força, equilíbrio, estabelecer diálogo, trabalho em equipe e controlar a ansiedade de querer buscar a bola e atravessá-la para o outro lado independentemente da ação dos demais.

d) Slackline (andar sobre a fita amarrada a 2 árvores, com a ajuda de um colega): trabalhar equilíbrio, propriocepção, trabalho em equipe, confiança, mobilidade em local instável.

e) Yoga, ginástica laboral e alongamento (prática inicialmente individual e finalizada com todo o grupo em roda, de mãos dadas, corpo junto e, de olhos 
fechados, fazendo movimento de onda): criar consciência corporal, fazer exercícios de respiração que provoquem bradicardia e sensação de relaxamento, descobrir o corpo e trabalhar a flexibilidade, aliviar tensões musculares, perceber as trocas de energia do corpo e estabelecer confiança - o aluno não irá cair ao fazer o movimento de onda-pêndulo, pois o colega está ao lado.

f) Exercícios de propriocepção (andar de olhos fechados, de costas, de lado sobre uma linha desenhada no chão, sendo guiados pelos colegas; fazer um circuito em trios, com os braças entrelaçados e de costas, transportando uma bola sem deixá-la cair; brincadeira do carrinho de mão): trabalhar a noção de corpo no espaço, auxílio mútuo, coordenação motora, resgate da ludicidade.

A partir das vivências realizadas, os alunos montavam uma espécie de portfólio no qual descreviam as atividades realizadas na aula, relatavam as sensações processadas com o corpo, faziam um relato por imagem e uma autoavaliação.

Nas imagensnarrativas a seguir, podemos perceber parte da dinâmica das aulas e alguns relatos de experiência dos alunos descritos nos portfólios. As imagens trazem narrativas próprias e nos provocam a pensar acerca das possibilidades de se trabalhar a Educação Física no Proeja de forma que essa disciplina faça sentido para os alunos adultos e traga reflexões acerca da vida e das relações de cooperação em detrimento da competição. Trata-se de Movimentos de re-existência!

Permitindo-se novos desafios e percebendo seus limites e possibilidades através das práticas corporais, os alunos ajudavam-se nas aulas e interagiam de forma espontânea, ficando livres para decidir se executariam, ou não, determinada prática, se teriam, ou não, auxílio dos colegas, se iriam, ou não, se permitir a tentar e a experimentar outras possibilidades do uso de seus corpos. Jogos cooperativos 
cumprindo seu papel na prática e potencializando, para além do lúdico, as aulas e a vida!

Algumas vivências antes inimagináveis para alguns se desenharam de forma inesperada e impactante, como o caso apresentado na Figura 6, em que a Dona O. permitiu-se, ajudada por colegas, a andar sobre a fita de Slackline - prática nunca antes experienciada por ela (e oportunidade para os demais de oferecerem auxílio, cooperação e estabelecimento de relação de confiança). Trata-se de currículos que transbordam o prescrito e se manifestam nos cotidianos em diferentes intensidades.

Respeito e solidariedade também são percebidos nas atitudes dos alunos que não se sentem à vontade, naquele momento, de realizar determinada prática (Figura 7). Corpos que fluem em suas subjetividades, afetos e afectos. Uma corporeidade que mostra suas marcas na cultura, nos desejos, nas expressões, negações, limites, possibilidades...

Manifestou-se uma relação de cumplicidade entre professor-aluno que permitiu trocas honestas e relatos sinceros. Problematizações emergiram a partir dos acontecimentos pontuais e trouxeram outras questões para a turma: é possível não fazer alguma atividade proposta na aula? Que negociações podem ser feitas entre aluno-aluno/aluno-professor? As práticas são seguras? Todos podem tentar? E se eu sentir medo, tenho a liberdade e autonomia de não fazer? Vou ser "mal" avaliado caso não faça alguma vivência? Como a cooperação e a ludicidade se desenham na prática nas propostas de aula apresentadas pela professora? Que reflexões podem ser feitas nesses espaçotempos de aprendizagemensinoaprendizagem? 
Figura 1: Portfólio de aluno - Tempo Chrónos e Aion: liberdade, burla, sinceridade. Fonte: Arquivo pessoal.

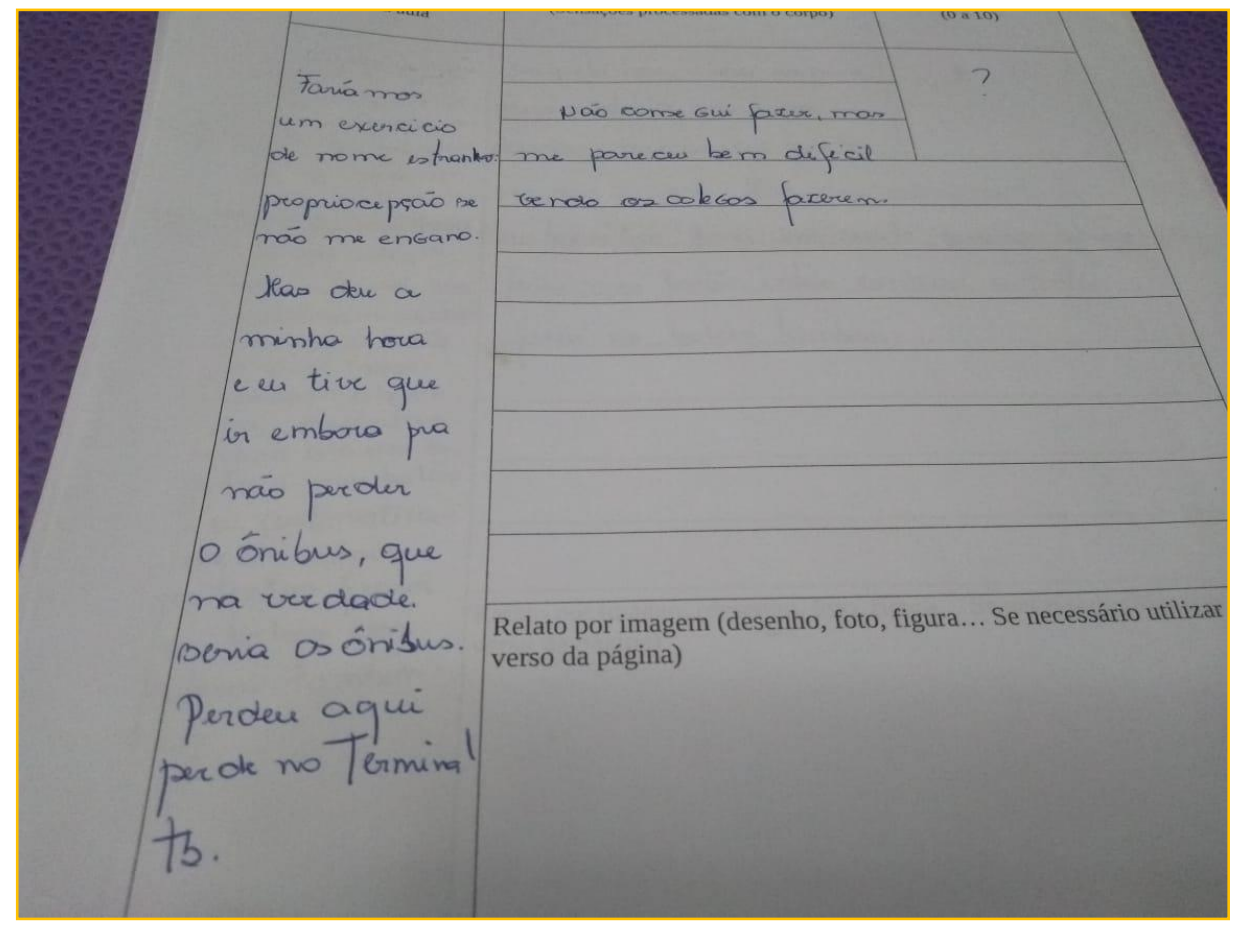

Situações assim mostram que os cotidianos são surpreendentes, que os sujeitos ordinários escapam, reinventam-se em astúcias, sutilezas, subversões (Figura 1). E, assim, vão potencializando o cuidado com o outro e as práticas de si. Maturana trata o amor como o fundamento emocional do social. Por meio do qual aceitamos o outro como legítimo outro na convivência.

"A emoção fundamental que torna possível a história da hominização é o amor. Sei que o que digo pode chocar, mas insisto, é o amor. Não estou falando com base no cristianismo. [...] O amor é o fundamento do social, mas nem toda convivência é social. O amor é a emoção que constitui o domínio de condutas em que se dá a operacionalidade da aceitação do outro como legítimo outro na convivência, e é esse modo de convivência que conotamos quando falamos do social. Por isso, digo que o amor é a emoção que funda o social. Sem a aceitação do outro na convivência, não há fenômeno social. Em outras palavras, digo que só são sociais as relações que se fundam na aceitação do outro como um legítimo outro na convivência, e que tal aceitação é o que constitui uma conduta de respeito" (MATURANA, 2009, p.23-24). 
Nos relatos apresentados, principalmente nas Figuras 2, 4, 5, e 8, colhemos alguns que merecem ser citados: "trabalho em equipe, um ajudando ao outro'; 'foi gratificante pois a vitória conquistada em grupo foi muito mais difícil por isso foi a melhor vitória'; ' 'antes de tomar qualquer decisão preciso pensar se não vou prejudicar alguém'; 'pensar no coletivo vale muito mais a pena'; 'uma lição para a vida'. Com isso, percebemos que as vivências corporais, através dos jogos cooperativos, potencializam o auxílio mútuo, a empatia, a colaboração, e o amor - ou seja, a conduta de respeito e legitimação do outro - e ampliam as possibilidades de ação no social. Escapam as aulas de Educação Física e tendem a tornar-se práticas de vida. É importante imbricar esses conhecimentos de forma que não ocorram apenas para cumprir um protocolo de aula, mas que sirvam para pensar sobre as práticas sociais que acontecem em outros espaços além do escolar.

Figura 2: Portfólio de aluno - Propriocepção: Afeto, alegria! Fonte: Arquivo pessoal.

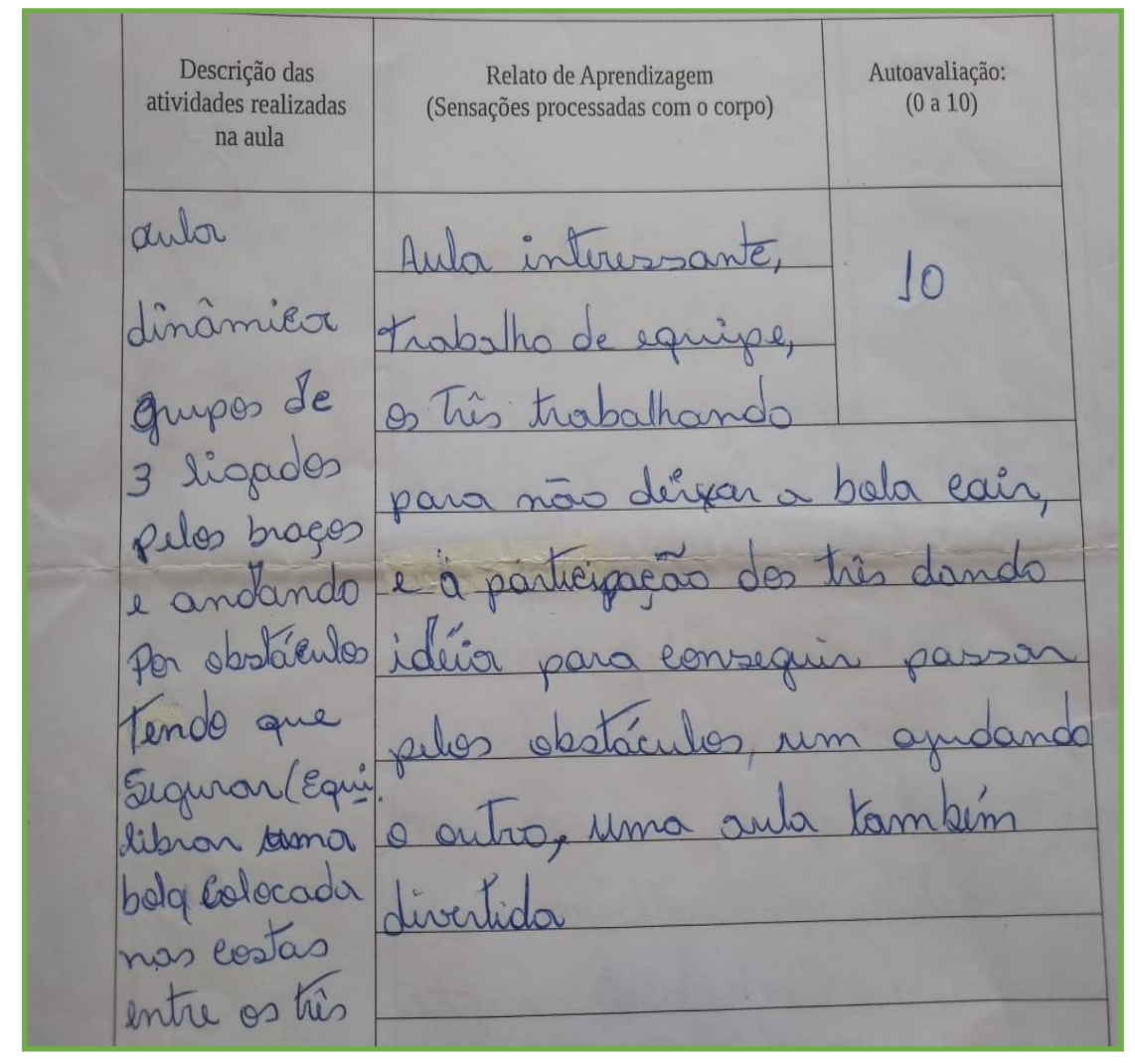


"Os registros do cotidiano são produzidos no calor dos acontecimentos; guardam as marcas de quem os escreveu; identificam a relevância atribuída a fatos e acontecimentos" (AZEVEDO, 2005, p. 160).

Figura 3: Trabalho em equipe: Vida como obra de arte! Fonte: Arquivo pessoal.

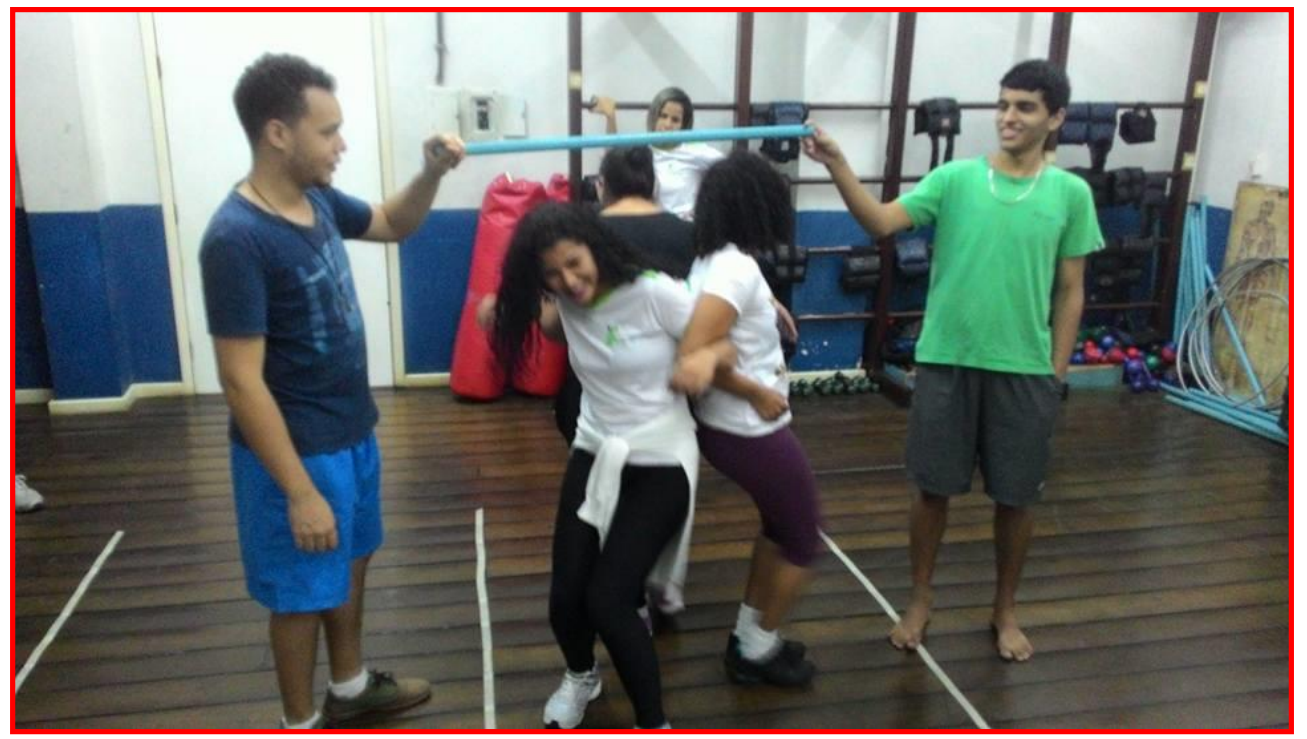

A proposta de trabalhar a propriocepção e atividades de equilíbrio em conjunto vai além da atividade em si de perceber o corpo, o movimento e o outro no espaço, antes, estimula a sinestesia ${ }^{4}$. Tratar a vida como obra de arte significa, também, perceber-se no mundo, em um agir política e eticamente engendrando novas formas de sentir, pensar, viver... "O pensamento jamais foi questão de teoria. Eram problemas da vida, Era a própria vida! (DELEUZE, 2013, p. 131).

Ao trabalhar os movimentos corporais através das interações, sensações e processos de cooperação, desenvolvemos novas habilidades para nos relacionarmos e mergulharmos com todos os sentidos em produções outras, produções de vida - que escapa, acontece e proporciona agenciamentos que nos tomam e traçam novos territórios (Figura 3).

\footnotetext{
${ }^{4}$ A sinestesia está associada com a mistura de estímulos relacionadas aos sentidos: tato, audição, olfato, paladar e visão. Sendo assim, estabelece uma relação de sensações interligadas entre planos sensoriais diferentes. 
Figura 4: Portfólio de aluno - Propriocepção: Quem sou eu no mundo? Quem são os outros? Podemos ser nós? Fonte: Arquivo pessoal.

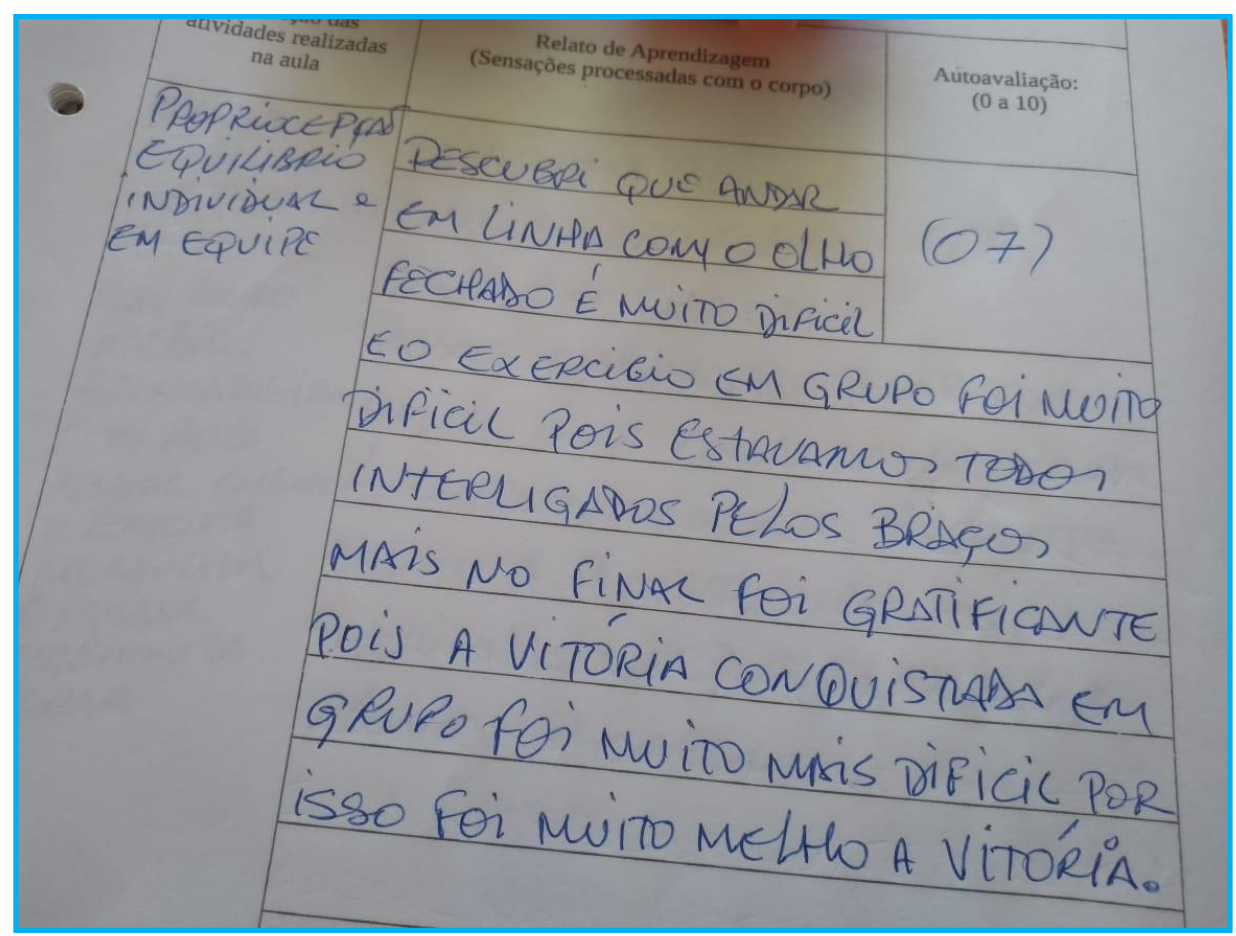

Em face da resposta do aluno, trazemos a citação de Maturana e Varela (1995) para quem devemos compreender o ser humano na dinâmica social e nos libertar da cegueira fundamental: a de não percebermos que só temos o mundo que criamos com o outro e que só o amor ajuda a criar esse mundo em comum. 
Figura 5: Portfólio de aluno - Dinâmica com balões: conhecimento e vida. É possível dissociálos? Fonte: Arquivo pessoal.

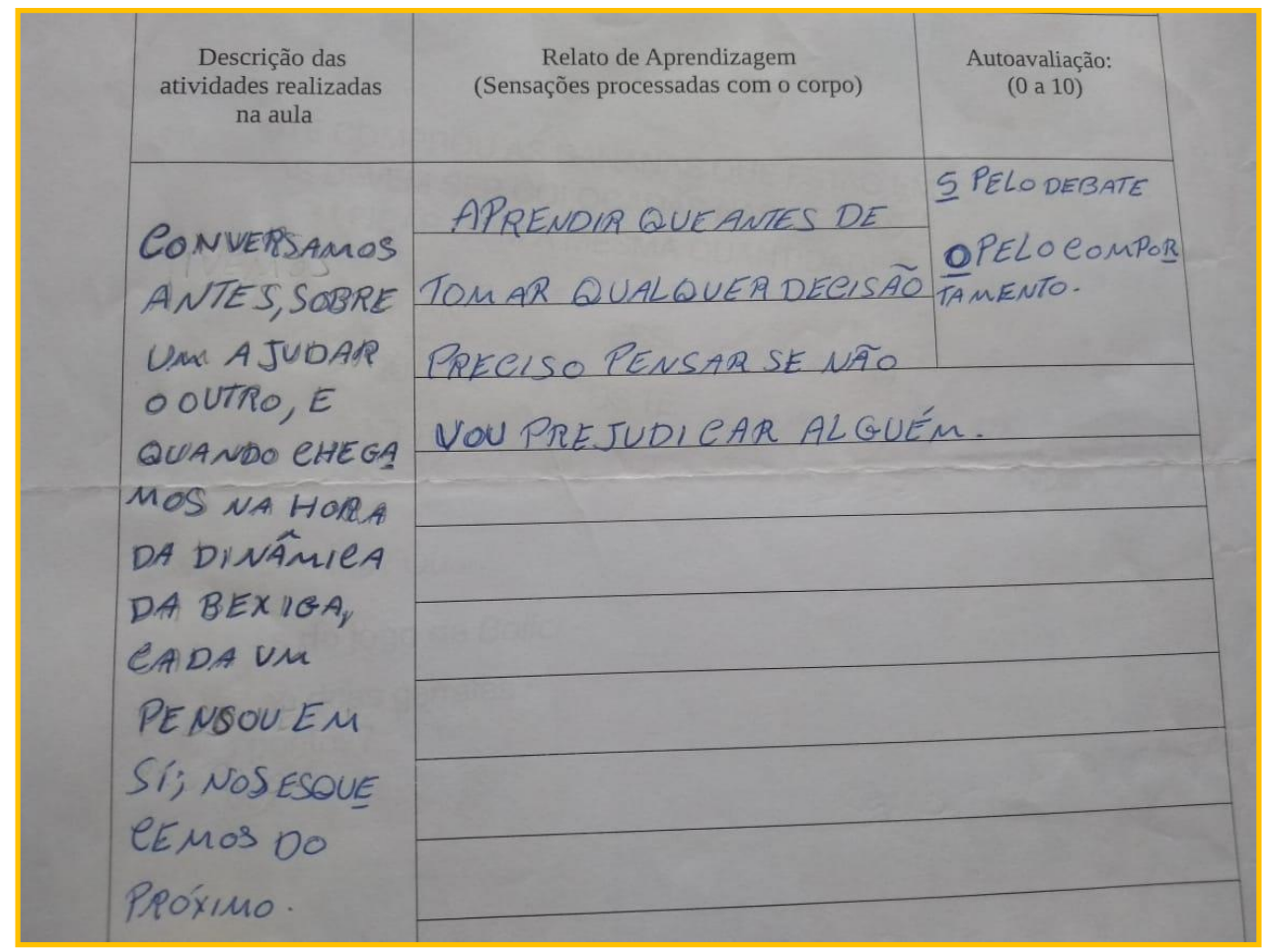

Se concordarmos com Maturana e Varela (1995) que conhecimento e vida são processos indissociáveis, defenderemos uma educação que os promova. Currículos que extrapolem o prescrito e que sejam tecidos conjuntamente, valorizando os caminhos percorridos por cada um em seus processos de subjetivação, serão o cerne dessa educação. "Viver e conhecer são mecanismos vitais, conhecemos porque somos seres vivos e isso é parte dessa condição. Conhecer é condição de vida na manutenção da interação ou acoplamentos integrativos com os outros indivíduos e com o meio." (RABELO, 2009, p. 08).

Podemos perceber nas conversações com os alunos e nos recortes de textos colhidos de seus portfólios os sentidos que exprimem ao pensar o cuidado de si em associação ao cuidado com o outro. São relações de afeto a partir das práticas corporais e das vivências. 
Figura 6: Auxílio mútuo. Confiança! Fonte: Arquivo pessoal.

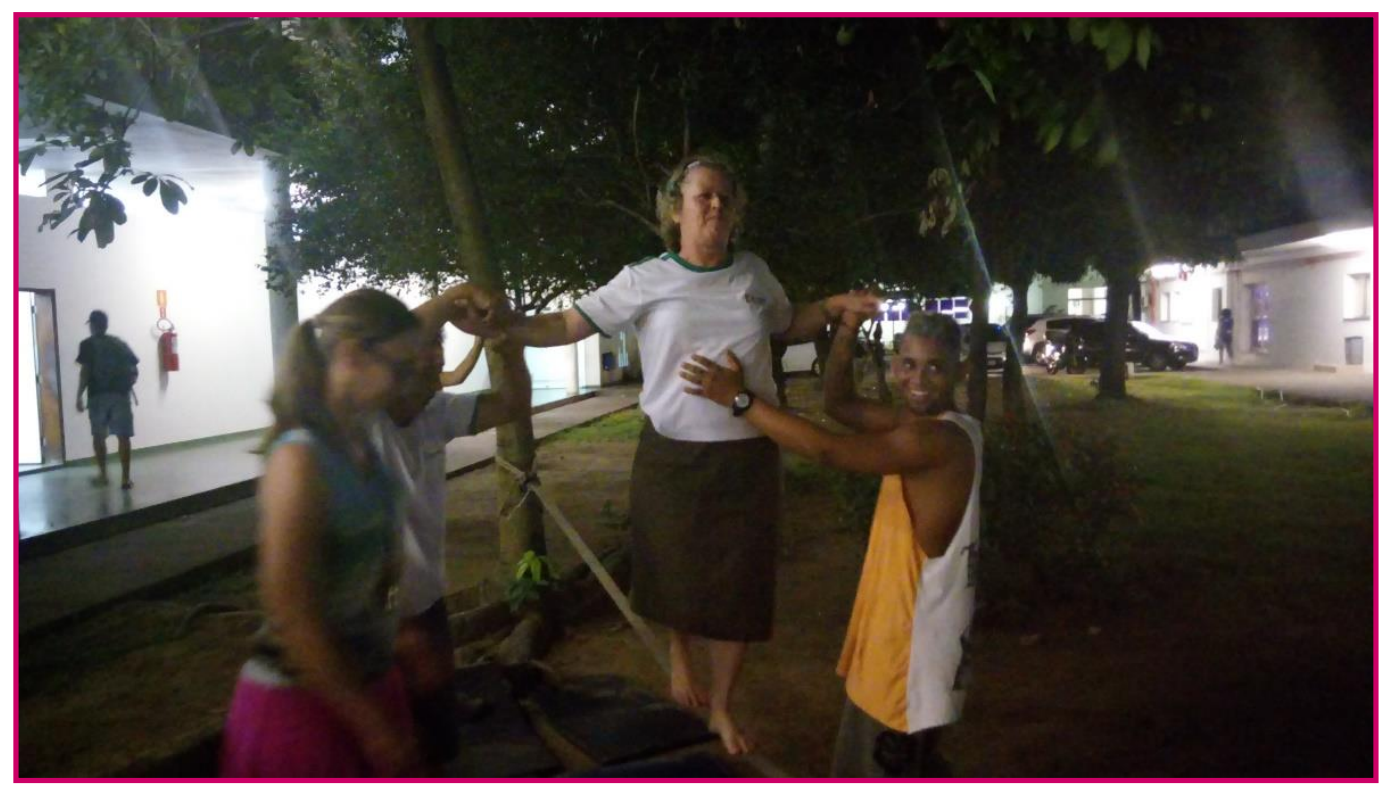

Figura 7: Respeito, equilíbrio, afecto. Estabilidade, desestabilização... Território! Fonte: Arquivo pessoal.

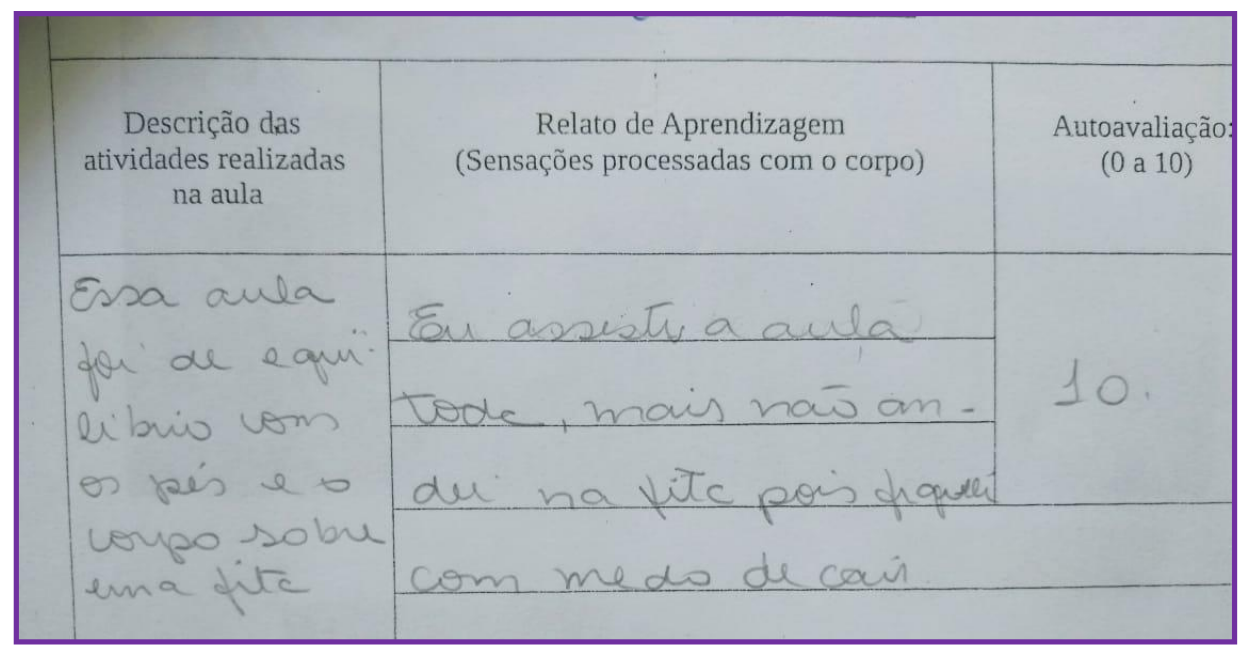


Figura 8: Portfólio de aluno - Propriocepção: Produção de uma vida bonita. Que a arte nos aponte uma resposta! Fonte: Arquivo pessoal.

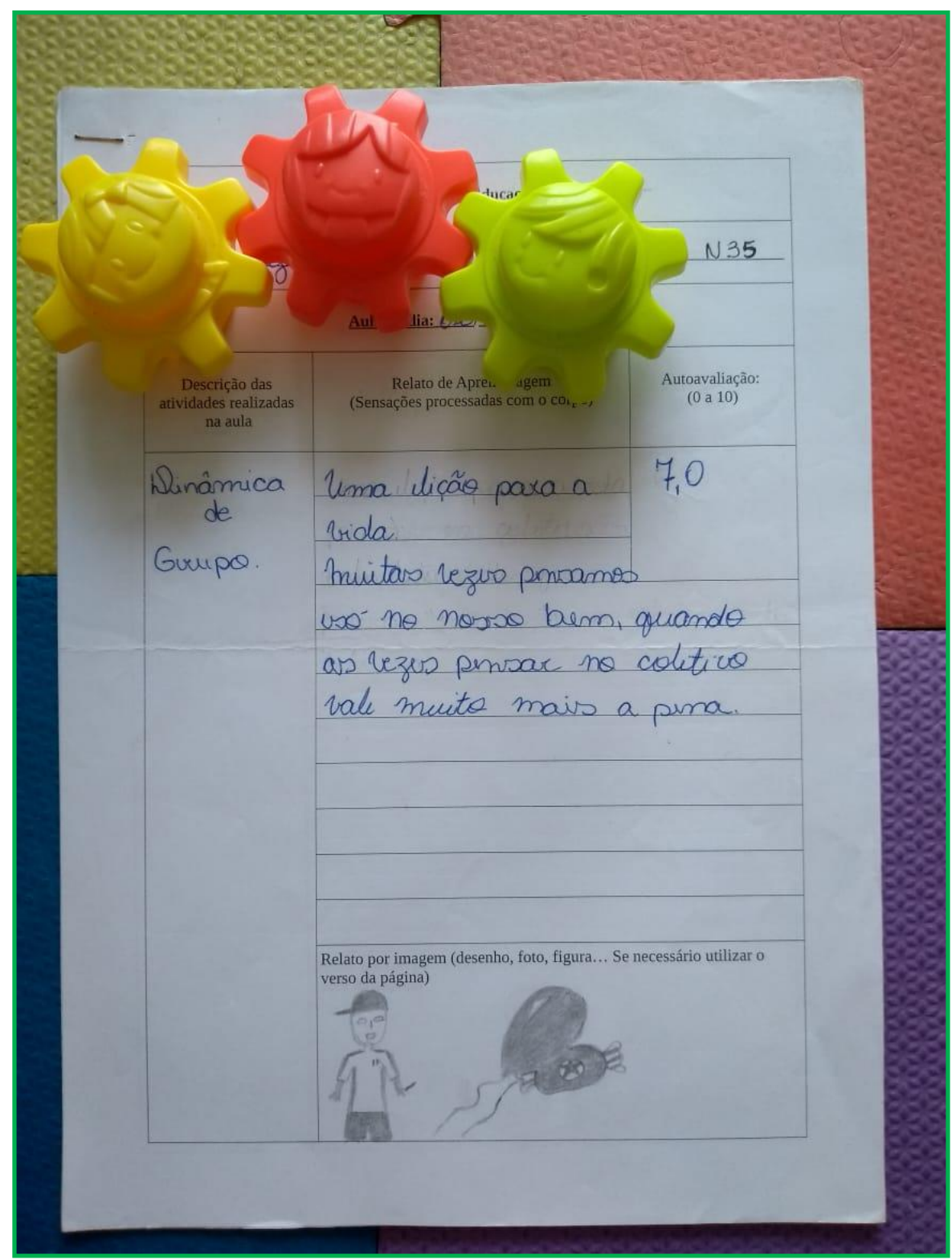


Figura 9: Portfólio de aluno - Futsal de mãos dadas: Ninguém solta a mão de ninguém! (No futsal e na vida...) Fonte: Arquivo pessoal.

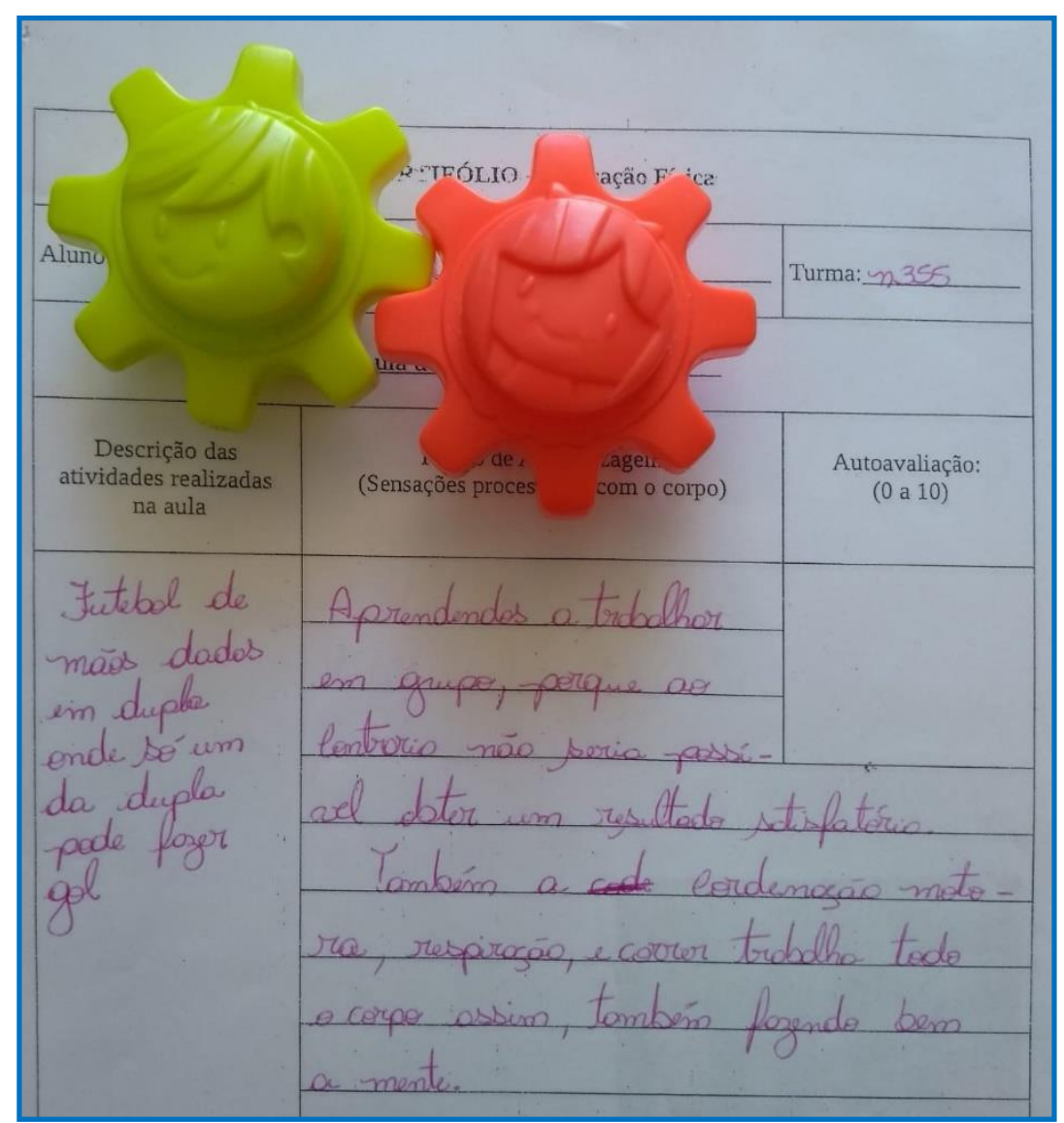

Figura 10: Portfólio de aluno - Futsal de mãos dadas: elo, conexão, caminhar junto... Fonte: Arquivo pessoal.

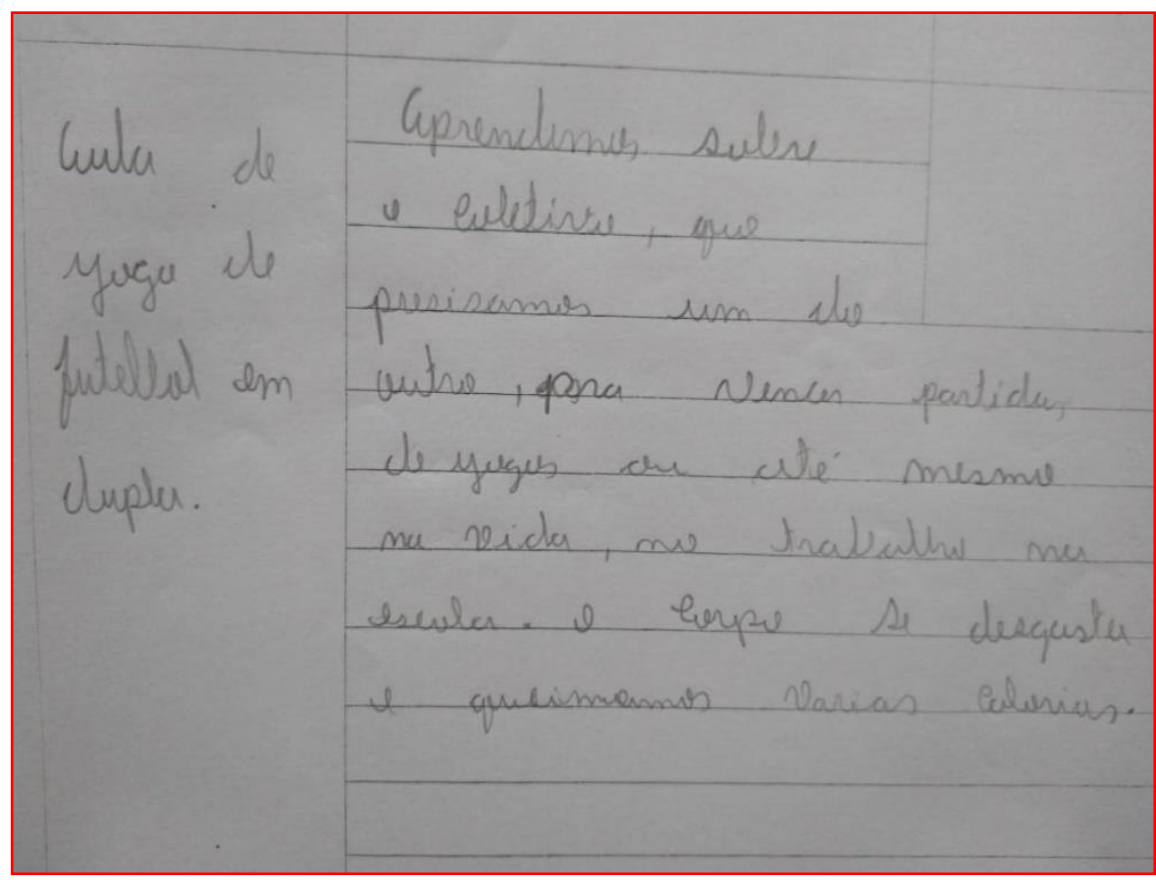


As figuras ajudam a nossa defesa de que o fazer curricular como produção de redes de sentidos que se constituem nas invenções, burlas, escapes e modos de ser, é significativo, conforme percebemos nos relatos dos alunos nos portfólios: "'três dando ideia para conseguir passar pelos obstáculos'; 'o exercício em grupo foi muito mais difícil[...] mas no final foi gratificante'; '5 pelo debate, 0 pelo comportamento'; 'não andei na fita pois fiquei com medo de cair'; 'precisamos um do outro para vencer partida de jogo ou até mesmo na vida, no trabalho, na escola'; 'deu a minha hora e eu tive que ir embora pra não perder o ônibus' (Figura 9, 10).

Seguimos desejosos de atravessamentos curriculares e construções discursivas que repensem os processos de subjetivação e os protagonismos dos alunos do Proeja tanto nas aulas de Educação Física quanto para além muros da escola (Figura 11).

"Os objetivos do trabalho pedagógico deixariam de ser apenas os de levar ao aluno alguns conhecimentos escolares clássicos formais e passariam a incorporar as possibilidades dos conteúdos de contribuírem para as ações concretas que os alunos devem ser capazes de desenvolver na sua vida cotidiana, tanto para melhorar sua própria qualidade de vida como para associar esta com a vida do conjunto da sociedade" (OLIVEIRA, 2007, p.98).

Figura 11: Redes. Cotidianos. Reinvenções. Compartilhando vida! Fonte: Arquivo pessoal.

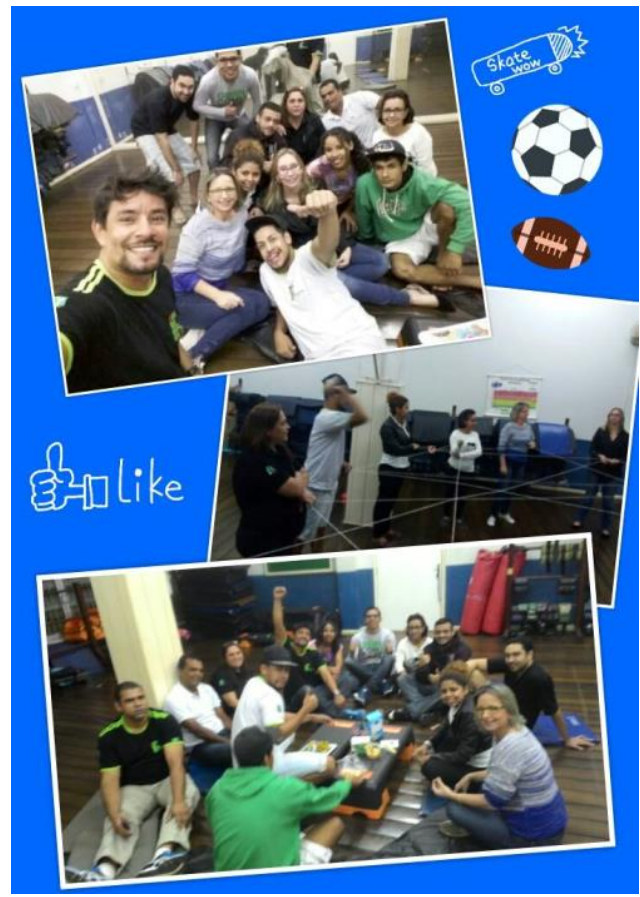




\section{CONSIDERAÇÕES FINAIS: SEgUIMOS DIALOGANDO...}

O debate é amplo e está longe de encerrar-se por aqui. Buscamos nas reflexões curriculares alternativas possíveis para o ensino da Educação Física para jovens e adultos e fazemos uma aposta político-epistemológica otimista.

Dessa forma, os movimentos de pesquisa com os alunos do Proeja despertam em nós a busca por currículos que se constituam nas redes cotidianas de interações, afetos e afecções.

Nossas trajetórias com o Proeja nos mostram que é importante resistir, no sentido Foucaultiano de re-existir, e também na ótica de Espinosa, quando afirma que o conhecimento é o mais potente dos afetos.

Se a competição é um fato, o que almejamos é buscar outras possibilidades... Já sabemos competir, necessitamos exercitar a cooperação em nossas ações diárias para buscar o cuidado de si na interação com o outro, respeitando-o como legítimo outra na convivência.

Assim sendo, o uso dos jogos cooperativos se mostra como ferramenta potente para questionarmos não só a ludicidade das vivências corporais em sala de aula, mas questões da vida em sociedade, despertando senso crítico e resgatando valores como igualdade, equidade, respeito mútuo e solidariedade.

\section{AGRADECIMENTOS}

O presente trabalho foi realizado com apoio parcial da Coordenação de Aperfeiçoamento de Pessoal de Nível Superior - Brasil (CAPES) - Código de Financiamento 001.

Agradecemos a Universidade Federal do Rio de Janeiro (UFRJ) e ao Instituto Federal do Espírito Santo (Ifes) pela oportunidade de pesquisar e aprender com os movimentos de resistência do Programa de Educação de Jovens e Adultos (Proeja). 


\section{REFERÊNCIAS}

ALVES, N. Decifrando o pergaminho - os cotidianos das escolas nas lógicas das redes cotidianas. In.: OLIVEIRA, Inês Barbosa; ALVES, Nilda (orgs.). Pesquisa nos/dos/com os cotidianos das escolas: sobre redes de saberes. Petrópolis, RJ: DP, 2008.

AZEVEDO, J.G. de. Arquivos institucionais e o cotidiano da escola. In: FERRAÇO, Carlos Eduardo. (Ed.). Cotidiano escolar, formação de professores (as) e currículo. São Paulo: Cortez Editora, 2008.

BROTTO, F. O. (2003). Jogos cooperativos: o jogo e o esporte como um exercício de convivência. 2. Ed. Santos-SP: Projeto Cooperação, 2003

BROTTO, F. O. Jogos cooperativos: "se o importante é competir, o fundamental é cooperar". São Paulo: Cepeusp. Ed. Re-Novada/Projeto Cooperação, 1999.

CERTEAU, M. D. A invenção do cotidiano. Artes de Fazer. Tradução Ephraim Ferreira Alves. Petrópolis, RJ: Vozes, 1994 v.1

DELEUZE, G. Mil platôs: capitalismo e esquizofrenia. Tradução de Aurélio Guerra Neto e Célia Pinto Costa. Rio de Janeiro: Editora 34, 1995 v.5.

DELEUZE, G. Espinosa: filosofia prática. Tradução de Daniel Lins e Fabien Pascal Lins. São Paulo: Editora Escuta, 2002.

DELEUZE, G. Conversações. São Paulo, SP: Editora 34, 2013.

FERRAÇO, C. E. (2008). A pesquisa em educação no/do/com o cotidiano das escolas. In: PEREZ, C.L.V.; OLIVEIRA, I.B. Aprendizagens cotidianas com a pesquisa: novas reflexões em pesquisa nos/dos/com os cotidianos das escolas. Petrópolis: DP et Alii, 2008.

FERRAÇO, C. E. (2011). Currículos em realização com os cotidianos escolares: fragmentos de narrativasimagens tecidas em redes pelos sujeitos praticantes. Currículo e educação básica: por entre redes de conhecimentos, imagens, narrativas, experiências e devires. Rio de Janeiro: Rovelle, 2011.

FOUCAULT, M. (1984). Sobre a genealogia da ética: uma revisão do trabalho. DREYFUS, P.; RABINOW, H. Michel Foucault: uma trajetória filosófica (para além do estruturalismo e da hermenêutica). Rio de Janeiro: Forense Universitária, 1984.

FOUCAULT, M. (1985). História da sexualidade 3: o cuidado de si. Rio de Janeiro: Graal, 1985.

KASTRUP, V. O funcionamento da atenção no trabalho do cartógrafo. Psicologia \& sociedade, v. 19 n. 1, p. 15-22, 2007.

LARROSA, J. Linguagem e educação depois de Babel. Tradução de Cynthia Farina. Belo Horizonte: Autêntica, 2004. 
MATURANA, H.; VARELA, F. A árvore do conhecimento: as bases biológicas do entendimento humano. São Paulo: Psy, 1995.

MATURANA, H. R. Emoções e linguagem na educação e na política. Belo Horizonte: Editora UFMG, 2009.

OLIVEIRA, I. B. D. Reflexões acerca da organização curricular e das práticas pedagógicas na EJA. Educar em Revista, v. 29, p. 83-100, 2007. 